\title{
NOTE
}

\section{Ontogenetic dietary shift of Japanese sea bass during larva-juvenile transition in Ariake Bay}

\author{
M. Shahidul Islam*, Masaru Tanaka
}

Laboratory of Estuarine Ecology, Field Science Education and Research Center, Graduate School of Agriculture, Kyoto University, Kyoto 606-8502, Japan

\begin{abstract}
Japanese sea bass Lateolabrax japonicus larvae and juveniles were collected from Ariake Bay in order to study changes in larval diets with increasing size and changing ontogeny. Larvae of 11 to $15 \mathrm{~mm}$ standard length (SL) (mainly postflexion) fed on small prey such as copepod nauplii, copepodites, adult Oithona davisae and other cyclopoids; no empty guts were recorded. Metamorphosing larvae (16 to $17 \mathrm{~mm} \mathrm{SL}$ ) consumed prey of intermediate (Paracalanus parvus) and larger (Acartia omorii, Sinocalanus sinensis, Tortanus derjugini, Calanus sinicus, Pseudodiaptomus marinus) sizes. The highest proportion of empty guts (42\%) was recorded at this stage. The frequency of empty guts decreased steadily with the establishment of foraging on larger prey. The contribution of larger prey to the diet increased with fish size, and an exclusive large prey diet was achieved at $24.0 \mathrm{~mm}$ SL after which the proportion of empty guts was minimal. We conclude that a critical period in Japanese sea bass may occur at metamorphosis during larva-juvenile transition, which is associated with an ontogenetic dietary shift from smaller to larger prey.
\end{abstract}

KEY WORDS: Ariake Bay - Critical period - Larva-juvenile transition - Japanese sea bass . Ontogenetic diet shift

\section{INTRODUCTION}

Food-mediated mortality is cited to be an important source of mortality in the early life of fishes and, therefore, a possible regulator of recruitment and year class strength. One potential source of food-mediated mortality during early larval life is the failure to establish feeding. Low prey densities or reduced prey capturing abilities could result in starvation of larvae or in weakened individuals that are susceptible to predation and other sources of mortality. Several hypotheses have been proposed to describe food-mediated mortality and to identify the period of larval life during which mortality may be concentrated (see Leggett \& DeBlois 1994 and references cited therein). Hjort's 'critical period' hypothesis was the first and most widely discussed hypothesis that proposed a causal link between feeding, larval survival, and recruitment (Hjort 1914, 1928). According to this hypothesis, the critical period corresponds to the transition of larvae from endogenous to exogenous feeding, and recruitment variability is regulated largely by the level of prey abundance at that time. Several reports suggest that critical periods in fish larvae may also occur at other intervals in the life history, such as metamorphosis (Vladimirov 1975, Blaxter 1988, Thorisson 1994, Chambers et al. 2001). Occurrence of a critical period during the first-feeding or other stages in Japanese sea bass is not known.

Body size or growth of young fish is frequently suggested to be related to survival and subsequent recruitment. Most studies on size- and growthdependent mortality of various species (e.g. Hovenkamp 1992, Rice et al. 1993, Meekan \& Fortier 1996) have concluded that fast growth enhances survival. Faster growing larvae are generally available to predators for a shorter period of time before metamorphosis to the juvenile stage (the 'stage duration' hypothesis; Anderson 1988, Cushing 1990). Therefore, 
achieving faster growth to rapidly become bigger (the 'bigger is better' hypothesis; Miller et al. 1988) is an important survival strategy in fish larvae. Fast growth may be achieved through size-selective foraging by fish that shift their diets from smaller to larger prey as they grow.

The Japanese sea bass Lateolabrax japonicus is a euryhaline marine fish distributed throughout the sea margin around Japan, and is an important species for commercial and recreational fisheries. In Ariake Bay, spawning of bass occurs in the middle part of the bay (shown in Fig. 1). The pelagic larvae are zooplanktivorous and feed predominantly on copepods, which are available over wide size spectra in the bay. Factors affecting larval survival and recruitment dynamics of Japanese sea bass, particularly the role of prey density, are largely unknown. In this study, we described sizeselective foraging and an ontogenetic dietary shift in Japanese sea bass larvae. We also identified the occurrence of a possible 'critical period' during the larvajuvenile transition that is associated with the dietary shift and may have potential demographic consequences.

\section{MATERIALS AND METHODS}

Ariake Bay, Japan (Fig. 1) is a shallow, semienclosed coastal bay with large tidal amplitude $(\sim 6.0 \mathrm{~m})$. This is the largest tidal wetland in Japan with an approximate area of $1700 \mathrm{~km}^{2}$. The bay receives water source from the East China Sea, the Pacific Ocean, and the Japan Sea. Water also drains into the bay as freshwater discharge through numerous channels. This is a well-mixed bay, supporting a dynamic and heterogeneous ecosystem with a unique biodiversity and important commercial fisheries. The shallow embayments and estuaries of the bay have high copepod abundance and are important nurseries for many fish species. Dominant copepods include Oithona davisae, Acartia spp., Calanus sinicus, Paracalanus parvus, and Pseudodiaptomus marinus that vary in size from $\sim 0.40 \mathrm{~mm}$ to $\sim 3.5 \mathrm{~mm}$ in length. Therefore, a wide range of sizes of copepods are available as prey for larval fishes in this ecosystem. However, O. davisae, a cyclopoid copepod, is the most abundant species and contributes nearly $50 \%$ to total copepod density throughout the year. The greatest concentrations of this small copepod correspond to areas where sea bass spawn (Okazaki et al. 2005), which suggests that this copepod may form an important part of the diet of firstfeeding bass larvae.

Sampling was conducted in the upper part of the bay, extending from the mouth of the Chikugo River to nearly $15.0 \mathrm{~km}$ downstream (Fig. 1). Sea bass larvae were collected by a total of 32 tows from 4 sampling stations during 4 cruises in the boreal spring season (Table 1) of 2001, using a larva net (1.3 m mouth diameter, $5 \mathrm{~m}$ long, $1 \mathrm{~mm}$ mesh at the body, and $0.33 \mathrm{~mm}$ mesh at the cod end). Samples were immediately fixed with $10 \%$ formalin at the sampling station. All larvae and juveniles were counted, measured (standard length: SL), and classified into developmental stages. Fish of 11.0 to $15.0 \mathrm{~mm}$ SL were composed of flexion and postflexion larvae; transition from larva to juvenile occurred at 16.0 to $17.0 \mathrm{~mm} \mathrm{SL}$, which coincided with metamorphosis; fish $>17.0 \mathrm{~mm}$ SL were considered to be juveniles. The digestive tracts (from esophagus to rectum) of individual larvae and juveniles were dissected with fine needles under a microscope. A total of 310 larvae and juveniles representing all available size groups were analyzed for gut contents. The digestive tracts were opened and food organisms were separated and examined at 2000× magnification. Prey organisms were counted and identified to the lowest possible taxonomic category. To determine gut content dry weights, gut contents were filtered through predried and pre-weighed filter papers (Whatman GF/F) and the filter papers were then dried in a thermostat oven at $45^{\circ} \mathrm{C}$ for $24 \mathrm{~h}$. Dry weights of the gut contents were determined from the difference in weights before and after filtration and drying.

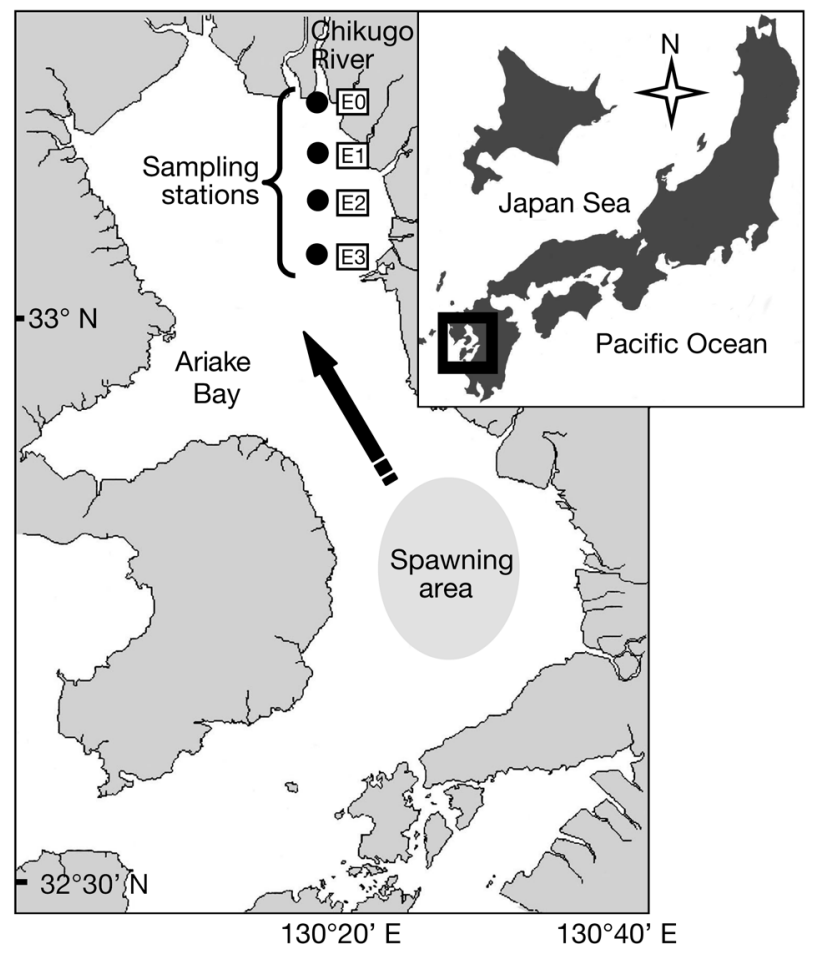

Fig. 1. Lateolabrax japonicus. Ariake Bay sampling stations (E0 to E3) and spawning grounds of Japanese sea bass 


\section{RESULTS}

A total of 1918 larvae and juveniles were collected by 32 tows, with an average density of 5.4 fish per $100 \mathrm{~m}^{3}$. Larvae ranged in size from 11.2 to $35.2 \mathrm{~mm} \mathrm{SL}$. Total numbers as well as fish density at each station and during each cruise are shown in Table 1. Mean $( \pm \mathrm{SD})$ fish density was $9.2 \pm 8.5,9.1 \pm 4.3,2.4 \pm 3.7$, and $0.8 \pm 0.4$ larvae and juveniles per $100 \mathrm{~m}^{3}$ on $11 \mathrm{March}$, 23 March, 10 April, and 22 April 2001, respectively.

A total of 9 major prey categories were identified. Prey categories were composed mainly of calanoid and cyclopoid copepods. They were Acartia omorii, Calanus sinicus, copepod nauplii and copepodite, Oithona davisae, Paracalanus parvus, Tortanus derjugini, Pseudodiaptomus marinus, and Sinocalanus sinensis (Fig. 2). There were 3 major size categories of prey. The smallest size category, which was comprised of O. davisae, copepod nauplii and copepodites, comprised the total diet of larvae of SL up to $\sim 16.0 \mathrm{~mm}$ (Fig. 2). Paravalanus parvus, which constituted the intermediate size category, was the major prey during the larva-juvenile transition and in young juveniles ranging in size from 16.0 to $18.0 \mathrm{~mm}$ SL (Fig. 2). Contribution of $P$. parvus to the diet dropped sharply in fish $>18 \mathrm{~mm} \mathrm{SL}$, when $S$. sinensis and A. omorii became dominant. The largest size category of prey was composed of A. omorii, S. sinensis, T. derjugini, C. sinicus, and $P$. marinus, with $A$. omorii overwhelmingly dominant (Fig. 2). These juvenile bass did not consume smaller prey such as $O$. davisae, nauplii, and copepodites, even though these prey were abundant in the environment. Therefore, strong selective foraging in larval and juvenile Japanese sea bass was observed, and the selective foraging was associated with prey

Table 1. Total number of bass larvae and juveniles, density (no. $\mathrm{m}^{-3}$ ) of bass larvae and juveniles and copepod density (no. $\mathrm{m}^{-3}$ ) at 4 sampling stations in the Chikugo estuary during 4 sampling cruises, 2001. See Fig. 1 for location of sampling stations E0 to E3

\begin{tabular}{|llrrrr|}
\hline Parameters & Cruise & E0 & E1 & E2 & E3 \\
\hline Total no. of & $11 \mathrm{Mar}$ & 153 & 121 & 160 & 347 \\
fish collected & $23 \mathrm{Mar}$ & 249 & 225 & 74 & 327 \\
& $10 \mathrm{Apr}$ & 20 & 6 & 11 & 182 \\
& $22 \mathrm{Apr}$ & 10 & 14 & 4 & 15 \\
Density of & $11 \mathrm{Mar}$ & 6.10 & 2.70 & 6.30 & 21.70 \\
fish $\left(\right.$ no. $\mathrm{m}^{-3}$ ) & $23 \mathrm{Mar}$ & 10.30 & 9.70 & 3.10 & 13.40 \\
& $10 \mathrm{Apr}$ & 0.90 & 0.30 & 0.50 & 7.90 \\
& $22 \mathrm{Apr}$ & 0.80 & 1.10 & 0.30 & 1.10 \\
Copepod density & $11 \mathrm{Mar}$ & 14146 & 33454 & 31532 & 34214 \\
(no. m $^{-3}$ ) & $23 \mathrm{Mar}$ & 987 & 881 & 520 & 1530 \\
& $10 \mathrm{Apr}$ & 9285 & 8856 & 8213 & 21795 \\
& $22 \mathrm{Apr}$ & 9541 & 6790 & 8935 & 19790 \\
\hline
\end{tabular}

size as is apparent from the result of prey length and weight in each size class (Fig. 2).

A dietary shift from smaller to larger prey occurred at 15.0 to $17.0 \mathrm{~mm} \mathrm{SL}$. Paravalanus parvus was an important prey of intermediate size during the dietary shift. The shift coincided with a high proportion of empty guts (Fig. 2). While no empty guts were recorded in 11 to $15 \mathrm{~mm}$ SL larvae, as much as $42 \%$ of
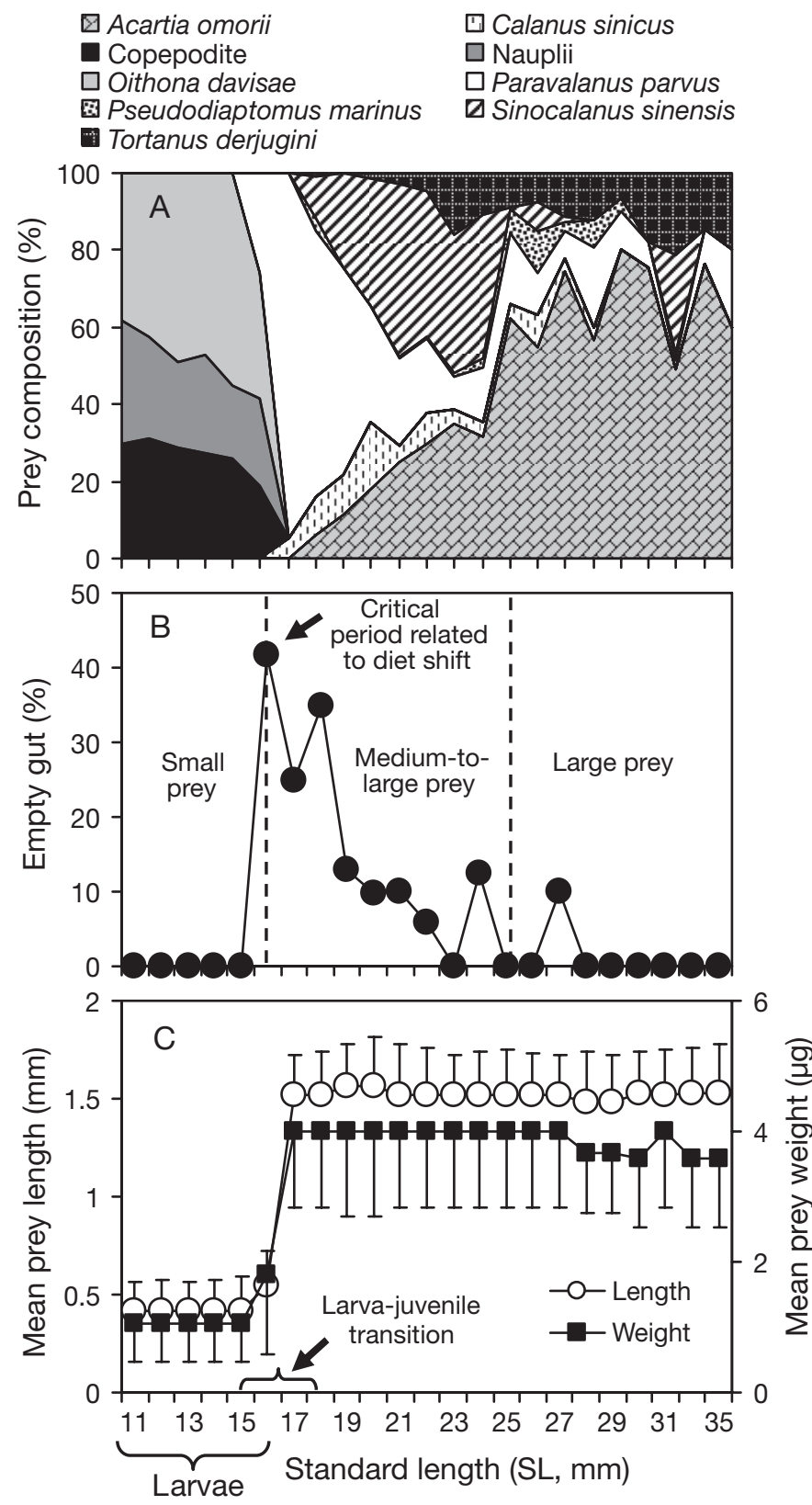

Fig. 2. Lateolabrax japonicus. (A) Numerical composition (\%) of prey items, (B) proportion (\%) of empty guts and (C) mean prey size (length $\mathrm{mm}$ and dry biomass $\mu \mathrm{g}$ ) in the guts in $1 \mathrm{~mm}$ SL classes of Japanese sea bass. Prey lengths and weights are mean $\pm \mathrm{SD}$ 
fish had empty guts at $16 \mathrm{~mm}$ SL during larva-juvenile transition. The incidence of empty guts dropped sharply with the onset of foraging on larger prey by larger juveniles. The proportion of empty guts stabilized again to a minimum (nearly $0 \%$ ) at $24 \mathrm{~mm} \mathrm{SL}$, which corresponded to a complete establishment of

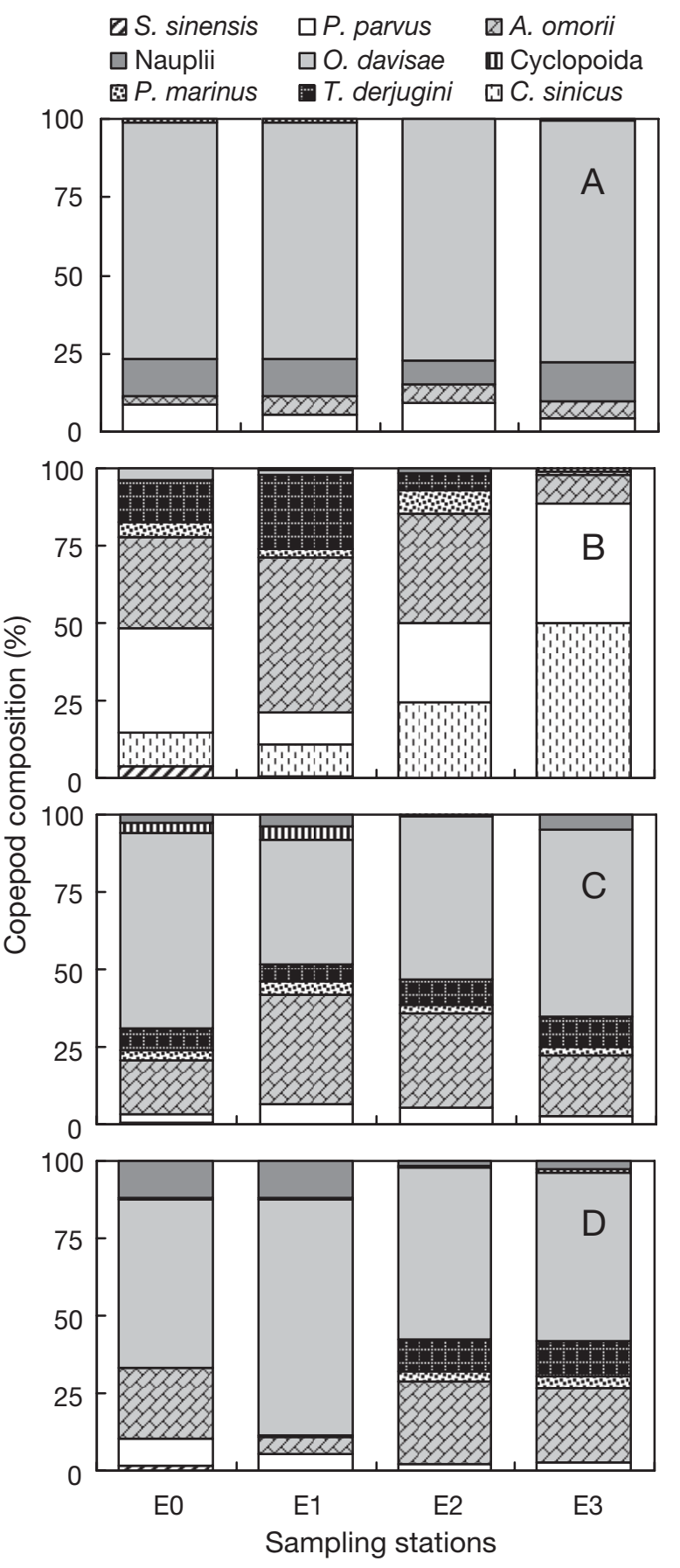

Fig. 3. Numerical composition of ambient copepods collected from 4 sampling stations in Chikugo estuary during 4 sampling cruises. (A) $11 \mathrm{March}_{\text {; }}$ (B) $23 \mathrm{March}_{\text {; }}$ (C) 10 April; (D) 22 April. See Fig. 2 legend for full genus names foraging on larger prey (Fig. 2). Thus, bass larvae and juveniles foraged on 2 completely different size groups of prey before and after the period of dietary shift. The smaller size group (mean length and weight: $0.415 \mathrm{~mm}$ and $1.05 \mu \mathrm{g}$, respectively) was comprised of Oithona davisae, copepod nauplii, and copepodites. The larger size group (mean length and weight: $1.53 \mathrm{~mm}$ and $3.9 \mu \mathrm{g}$, respectively) was composed of the other prey copepod species (Fig. 2).

Copepods in the environment were overwhelmingly dominated by Oithona davisae, followed by Acartia omorii, Paravalanus parvus, Calanus sinicus, Tortanus derjugini, copepod nauplii, copepodite, Pseudodiaptomus marinus, and Sinocalanus sinensis (Fig. 3). Copepod density at each station and during each cruise is given in Table 1. A fairly high density of copepods occurred throughout the sampling periods. Mean copepod density was $28.3( \pm 9.5) \times 10^{3}, 0.98( \pm 0.42) \times$ $10^{3}, 12.0( \pm 6.5) \times 10^{3}$, and $13.1( \pm 5.8) \times 10^{3} \mathrm{~m}^{-3}$ on 11 March, 23 March, 10 April, and 22 April 2001, respectively.

\section{DISCUSSION}

Development in fishes can be complicated, particularly in those species that undergo several larval stages and end with completed metamorphosis, which is the case in most marine fishes (Thorisson 1994). Premetamorphic larvae are small, have small mouths, and their digestive system lacks a stomach (Tanaka 1971). First-feeding larvae usually consume small prey items such as nauplius and copepodite stage or adults of smaller copepods (Oithona davisae in the present study). Since metamorphosis is associated with morphological, physiological, and behavioural restructuring, a substantial amount of energy is required and consumed during this process (Thorisson 1994, Tanaka et al. 1996). In addition to the energy that is constantly used for maintenance and growth, extra energy is required during metamorphosis to remodel larval structures into the juvenile form (Thorisson 1994). This increasing energy demand could be met by a combination of 2 means: (1) by increasing feeding intensity, i.e. capturing and consuming more prey, and (2) by shifting the diet toward larger prey. Although both processes may occur, capturing more prey is generally a process that requires further energy. Therefore, in areas where prey items are available over wide size ranges, a dietary shift from smaller to larger prey would be a better choice because this would produce more energy per unit of effort and, therefore, higher net benefit for maximizing growth (Thorisson 1994, Dahlgren \& Eggleston 2000).

However, the very small and developing stomachs of metamorphosing larvae are likely to be incapable of 
taking larger prey (Tanaka 1971, Thorisson 1994). Foraging on larger prey may also be limited by other factors such as the gape size (DeVries et al. 1998), which is generally small in small larvae. This might be the reason why pre-metamorphic larvae preyed mainly on the smallest copepod Oithona davisae, whereas postmetamorphic juveniles preyed on larger prey such as Paravalanus parvus, Acartia omorii, Sinocalanus sinensis, and Calanus sinicus, despite high abundance of $O$. davisae in the ambient water. This pattern is consistent with many optimal foraging models concerned with prey selection that have suggested that predators should actively choose to include certain prey types in their diets and reject others (Greene 1986), in order to maximize growth that enhances the chance of survival (Dahlgren \& Eggleston 2000). However, generalization of the foraging behavior in fishes is difficult, because foraging in larval and juvenile fishes is affected by numerous factors biotic, abiotic and geographical (Dahlgren \& Eggleston 2000, Dowling et al. 2000, Puvanendran et al. 2004).

We observed that relatively high frequencies of empty stomachs were concentrated around the time of metamorphosis. Higher rates of empty stomachs might be caused by one or a combination of the following reasons: (1) more rapid metabolism because of high energy demand during metamorphosis; (2) cessation of feeding despite prey availability; (3) reduced ability to forage; and (4) low availability of prey of suitable size. Although a considerable amount of literature is available on the morphological, physiological, and nutritional changes associated with metamorphosis in different fish species, empirical evidence of ontogenetic changes in foraging behavior and prey selectivity in the field is relatively sparse. Many studies on ontogenetic changes in the diet of larval and juvenile fishes suggest that dietary shift follows habitat shift, related to settlement from pelagic to benthic habitats (Huessy et al. 1997, Lomond et al. 1998, Link \& Garrison 2002). However, very few studies have attempted to relate dietary shift with frequencies of empty stomachs. In absence of sufficient literature, we suggest that the high frequency of empty stomachs in metamorphosing larvae might be associated with prey size.

The mean size of the largest prey category that we observed was at least 3 times larger than the mean size of the smaller category diet, indicating the importance of an intermediate size prey category during the dietary shift. Although Paravalanus parvus was used as a major prey item during the transition, this copepod does not appear to be sufficient as an intermediatesized prey because the size difference between this prey and the smaller prey category was only $0.13 \mathrm{~mm}$; furthermore, it was not as abundant as Oithona davisae (P. parvus $15 \%$ versus $O$. davisae $42 \%$ of aver- age total copepod abundance at the sampling stations). This lack of suitable prey resulted in a large proportion of larvae with empty guts during the transition period. The small amounts of food and large proportions of empty guts clearly indicate reduced feeding activities of metamorphosing bass. Although growth rates were not measured during this study, it is reasonable to assume that the reduced feeding activities might have obvious impacts on the growth of metamorphic bass, resulting in a reduced potential for survival for this life stage. High proportions of empty guts thus indicate the occurrence of a possible critical period during the larva-juvenile transition of Japanese sea bass in Ariake Bay, which may be caused by the lack of suitable intermediated-size prey during the process of dietary shift from smaller to larger prey. Larvae passing though this critical period may experience a high level of foodmediated mortality, directly from starvation and indirectly from predation on starved and weakened larvae.

To date, no information is available on the first feeding of Japanese sea bass larvae in the field, and any critical period related to prey availability during the first feeding is not known. From a spatial comparison of copepod nauplii in Ariake Bay, Okazaki et al. (2005) reported the highest density of nauplial copepods (mainly Oithona davisae) to be in areas where higher densities of first-feeding larvae are likely to occur (between the upper and middle part of the bay). From high abundance of smaller prey of several types, we assume that first feeding is not limited by prey availability. Occurrence of a critical period at metamorphosis has been reported by several researchers (see Thorisson 1994). In a review, Vladimirov (1975) provided evidence of a critical interval at or close to metamorphosis. Blaxter (1988) suggested 5 potentially critical periods including metamorphosis, and Sette (1943), when studying the survival of Atlantic mackerel Scomber scombrus, stated that if 1 period is to be singled out as the most critical, it must be the period during the transition from larval to post-larval stages. Available literature suggests that critical periods in fishes are not restricted to first-feeding larvae: they may occur during metamorphosis or other parts of the life history and show obvious species variations. Even within a single species, the timing of critical periods may be regionally variable, depending on the variability in hydrodynamic conditions, prey composition and density, and the habitat use pattern by the fish. Although we did not attempt to relate the high frequencies of empty guts with mortality, we assumed that the metamorphosis of bass is particularly hazardous because of poor feeding conditions and high energy demands. Thus, physiological and other transformations associated with metamorphosis may give rise to new types of behavior (Amara \& Galois 2004). 
Moreover, high rates of empty stomachs suggest high susceptibility to starvation, poorly conditioned larvae, and reduced probability of survival. Thus, we view metamorphosis as a critical period for Japanese sea bass in Ariake Bay. This critical period corresponds to the dietary shift from smaller to larger prey.

Acknowledgements. This study was supported by a research grant from the Japanese Government Ministry of Education, Culture, Sports, Science and Technology (Monbukagakusho, MEXT); M.S.I. acknowledges financial support provided by MEXT (through the 'Monbukagakusho Scholarship') during his stay in Japan. We gratefully acknowledge the comments of anonymous reviewers that tremendously improved our manuscript.

\section{LITERATURE CITED}

Amara R, Galois R (2004) Nutritional condition of metamorphosing sole: spatial and temporal analysis. J Fish Biol 64: 72-88

Anderson JT (1988) A review of size-dependent survival during pre-recruit stages of fishes in relation to recruitment. J NW Atl Fish Sci 8:55-66

Blaxter JHS (1988) Patterns and variety in development. In: Hoar WS, Randall DJ (ed) Fish physiology, Vol 11. The physiology of developing fish. Part A. Eggs and larvae. Academic Press, London, p 1-58

Chambers RC, Witting DA, Lewis SJ (2001) Detecting critical periods in larval flatfish populations. J Sea Res 45:231-242

Cushing DH (1990) Plankton production and year-class strength in fish population: an update of the match/mismatch hypothesis. Adv Mar Biol 26:249-293

Dahlgren CP, Eggleston DB (2000) Ecological processes underlying ontogenetic habitat shifts in a coral reef fish. Ecology 81:2227-2240

DeVries DR, Stein RA, Bremigan T (1998) Prey selection by larval fishes as influenced by available zooplankton and gape limitation. Trans Am Fish Soc 127:1040-1050

Dowling NA, Hall SJ, Mitchel JG (2000) Foraging kinematics of barramundi during early stages of development. J Fish Biol 57:337-353

Greene CH (1986) Patterns of prey selection: implications of predator foraging tactics. Am Nat 128:824-839

Hjort J (1914) Fluctuations in the great fisheries of northern Europe reviewed in the light of biological research. Rapp PV Réun Cons Int Explor Mer 20:1-128

Editorial responsibility: Howard I. Browman (Associate Editorin-Chief), Storebø, Norway
Hjort J (1928) Fluctuations in the year classes of important food fishes. J Cons Perm Int Explor Mer 1:5-38

Hovenkamp F (1992) Growth-dependent mortality of larval plaice Pleuronectes platessa in the North Sea. Mar Ecol Prog Ser 82:95-101

Huessy K, St. John MA, Boettcher U (1997) Food resource utilization by juvenile Baltic cod Gadus morhua: a mechanism potentially influencing recruitment success at the demersal juvenile stage? Mar Ecol Prog Ser 155:199-208

Leggett WC, DeBlois E (1994) Recruitment in marine fishes: is it regulated by starvation and predation in the egg and larval stages? Neth J Sea Res 32:119-134

Link JS, Garrison LP (2002) Trophic ecology of Atlantic cod Gadus morhua on the northeast US continental shelf. Mar Ecol Prog Ser 227:109-123

Lomond TM, Schneider DC, Methven DA (1998) Transition from pelagic to benthic prey for age group 0-1 Atlantic cod, Gadus morhua. Fish Bull 96:908-911

Meekan MG, Fortier L (1996) Selection for fast growth during the larval life of Atlantic cod Gadus morhua on the Scotian Shelf. Mar Ecol Prog Ser 137:25-37

Miller TJ, Crowder LB, Rice JA, Marschall EA (1988) Larval size and recruitment mechanisms in fishes: toward a conceptual framework. Can J Fish Aquat Sci 45: $1657-1670$

Okazaki Y, Hosoe Y, Nonaka Y, Nakata H (2005) Spatial and temporal distribution of copepod in Ariake Bay. Bull Jpn Soc Fish Oceanogr 69:10-17

Puvanendran V, Salies K, Laurel B, Brown JA (2004) Sizedependent foraging of larval Atlantic cod (Gadus morhua). Can J Zool 82:1380-1389

Rice JA, Miller TJ, Rose KA, Crowder LB, Marschall EA, Trebitz AS, DeAngelis DL (1993) Growth rate variation and larval survival: inference from an individual-based size-dependent predation model. Can J Fish Aquat Sci 50: $133-142$

Sette OE (1943) Biology of the Atlantic mackerel, Scomber scombrus, of North America. US Fish Bull 38:149-236

Tanaka M (1971) Studies on the structure and function of the digestive system in teleost larvae. III. Development of the digestive system during postlarval stage. Jpn J Ichthyol 18:164-174

Tanaka M, Kawai S, Seika T, Burke JS (1996) Development of the digestive organ system in Japanese flounder in relation to metamorphosis and settlement. Mar Freshw Behav Physiol 28:19-31

Thorisson K (1994) Is metamorphosis a critical interval in the early life of marine fishes? Environ Biol Fish 40:23-36

Vladimirov VI (1975) Critical periods in the development of fishes. J Ichthyol 15:451-468

Submitted: October 30, 2005; Accepted: April 4, 2006

Proofs received from author(s): September 12, 2006 